\title{
Derechos Humanos y Cultura en el Siglo XXI: las Áreas Declaratorias de Derechos
}

\author{
Flor María Avila Hernández *
}

Resumen: Los recientes desarrollos de los derechos humanos en los niveles normativos nacionales e internacional, a partir de la mitad del siglo XX, la nueva conciencia creciente de individuos y comunidades en torno a los mismos, el debate emergente a nivel civil, gubernamental e intergubernamental, el mayor número de actores sociales y políticos involucrados en su promoción y defensa, pareciera sumergirnos en una "cultura de derechos humanos" con proyección revolucionaria. Nuestra hipótesis de investigación es que las recientes cartas de Derechos Humanos de las Democracias Occidentales y del Islam, a partir de la década de los ochenta, no responden a verdaderos proyectos de institucionalidad de la vida en común, sino que obedecen a la lógica discursiva de los Estados nacionales, en la búsqueda de consenso y legitimidad democrática en el foro internacional, con el resultado de ocultar los deficit de democracia, el desvalor de la vitalidad y la disgregación social, que las teorías conflictualistas sobre derechos humanos denuncian.

Palabras-clave: Derechos Humanos, Cultura, Cartas de Derechos, Islam, Democracia

Abstract: 20th Century recent developments on Human rights on a normalized national and international level with a new grown conscience of individuals, its surrounding communities and rising debate on a civil, governmental and intergovernmental level. Thus, a higher number of social and political actors involved on its promotion and defense, submerge us on a culture of human rights with revolutionary projection. As hypothetical investigation, recent human rights declarations of the 1980's from Occidental societies and Islam do not correspond with real projects of the institution of common life. In contrast, they obey a logical discussion from national states, in search of consensus and democratic legitimacy on the international forum, with democracy deficits, unworthy vitality and social desegregation, as hidden results; as denounce by conflictive human rights theories.

Keywords: Culture, Human Rights Declarations, Islam, Democracy

* Profesora do Instituto de Filosofia del Derecho "Dr. J. M. Delgado Ocando", Sección de Sociología Jurídica - Facultad de Ciencias Jurídicas y Políticas de la Universidad del Zulia - Maracaibo/Venezuela. E-mail: @fmavila@iamnet.com. Recebido em 28/10/05 e aceito em 15/12/2005 


\section{Apariencia de una cultura de derechos humanos en formación}

Los recientes desarrollos experimentados por los derechos humanos en los niveles normativos nacionales e internacional, principalmente a partir de la mitad del siglo pasado con la génesis de un corpus iuris internacional y sus últimas conquistas, la nueva conciencia creciente en torno a los mismos de individuos y comunidades, el debate emergente a nivel civil, gubernamental e intergubernamental, el mayor número de actores sociales y políticos involucrados en la promoción y defensa de los derechos humanos, pareciera sumergirnos en una cultura con proyección revolucionaria, que pudieramos llamar "cultura de los derechos humanos". Una cultura que tiene como centro al hombre, la sacralidad e inviolabilidad de su dignidad humana y su protección y garantía por parte del Estado. Una cultura que tiene como novedad histórica la elaboración colectiva por parte de los gobiernos de un "corpus iuris" así como el empeño de todas las agencias para su actuación.

Por otra parte, el impacto de las graves violaciones de los derechos humanos sobre la opinión pública, el proceso de mundialización con la ampliación de los horizontes de referencia políticos, económicos y culturales así como el cambiamiento de la realidad tecnológica y multimedial que transforma día a día las relaciones y percepciones de aproximación/lejanía, intimidad/extrañeza, pertinencia/aferencia, ha creado el escenario propicio para la circulación de los más variados discursos sobre derechos humanos, en los cuales se confrontan las diversas cosmovisiones y los ideales de vida en común. Este proceso de "transición cultural acelerada" es al mismo tiempo base de nuevos conflictos, incertidumbres y amenazas.

La historia de los derechos humanos por su parte, nos presenta un cuadro amplio de diversas áreas declaratorias, conformadas a partir de los desarrollos de las declaraciones de derechos humanos, las cuales constituyen "la enunciación solemne de los principios, de los valores y de las necesidades que proponen modelos o establecen los fundamentos para las Instituciones de la vida en común". (CAPOZZI, 1998, p. 417).

Estas grandes áreas han sido identificadas por el distinguido profesor Gino Capozzi de la escuela praxeológica napolitana en las siguientes: - Area de las Democracias Occidentales - Area del Socialismo Real y el Area del Islam. 
La primera área tiene como cartas emblemáticas la Bills of Rights inglesa de 1689, la Carta Magna de los Derechos Humanos, también conocida como la Declaración Francesa de los Derechos del Hombre y del Ciudadano de 1789 y la Declaration of Independence de los Estados Unidos de 1776.

El área del Socialismo Real tiene como carta emblemática la "Declaración de los Derechos de los Trabajadores y de los Oprimidos” de 1918.

El área del Islam tiene como cartas más representativas la "Declaración Universal Islámica sobre Derechos Humanos" de 1981 y la "Declaración del Cairo sobre los Derechos Humanos en el Islam" de 1990.

La articulación de las diversas áreas declaratorias, a través de la circulación de diversos valores, ha llevado a una confrontación esencialmente bilateral y en apariencia conflictiva entre el área de las democracias occidentales y el área del Islam, viniendo a menos el área del Socialismo Real ${ }^{1}$, después de la caída del muro de Berlín, con la consiguiente fragmentación de la Unión Soviética y los cambios en las estructuras económicas de los países asiáticos.

La hipótesis de investigación que formulamos es que las recientes cartas de Derechos Humanos de las áreas antes mencionadas, a partir de la década de los ochenta, no responden a verdaderos proyectos de institucionalidad de la vida en común, sino que obedecen a la lógica de los Estados nacionales, en la búsqueda de consenso y legitimidad democrática en el foro internacional, con el resultado de ocultar los déficit de democracia, el desvalor de la vitalidad y la disgregación social, que las teorías conflictualistas denuncian.

Después de la Declaración Universal de los Derechos Humanos de las Naciones Unidas de 1948, que signa el compromiso entre los dos sistemas históricos y materiales de los derechos, seguido por una intensa expansión del derecho internacional de los derechos humanos, asistimos al desarrollo de la "regionalización y sectorialización" de los derechos, como afirma el profesor italiano Antonio Cassese.

La regionalización de los derechos humanos se manifiesta en el proceso de institucionalización de los organismos regionales de tutela de los derechos

\footnotetext{
${ }^{1}$ Este gran espacio tiene como matriz principal la "Declaración de los Derechos de los Trabajadores y de los Oprimidos" votada y aprobada por el Congreso de las Repúblicas Socialistas Soviéticas en 1918. La Declaración soviética es también una transcripción de historia por cuanto constituye la conclusión de la "lucha de clases" de la clase obrera a través del "reconocimiento del valor trabajo en relación a la plusvalía del capital como pertenencia de los propietarios de los instumentos de producción" (CAPOZZI, 1998, p. 408). Pocos países en el mundo reflejan este modo de ser de la vida en común, como por ejemplo, Cuba y Corea del Norte.
} 
como en el caso de Europa, América Latina y África, y en forma embrional también en Asia. La regionalización marca el pasaje desde las cartas de los derechos hasta la actuación reforzada de los derechos humanos en el plano regional, especialmente con la colaboración entre Estados que se reconocen semejantes y disponen de una historia y de tradiciones comunes.

De igual forma, este proceso de formación de los sistemas regionales de tutela en los grandes espacios, sistemas que han tenido como función principal fortalecer y complementar la tutela estatal de la persona, como individuo y comunidad, pone en evidencia la intensificación de la necesidad común de los Estados de conseguir mayor autonomía y legitimación, tanto en el plano nacional como en el internacional. En otras palabras, los derechos humanos constituyen, en el hacer de las instituciones y en cada uno de los espacios, una solicitud y petición para el fortalecimiento de los Estados en el perfil de sus identidades.

Por otro lado, la sectorialización de los derechos humanos destaca el proceso de particularización de los derechos, es decir, del pasaje desde la generalidad y abstracción característica del lenguaje de las Cartas de los Derechos hasta la especificidad de los derechos que tutelan y protegen en forma diferenciada los intereses particulares de grupos o categorías de personas en función de las necesidades.

Este proceso de sectorialización se ha evidenciado en los grandes espacios, especialmente con la intensificación de la producción de nuevos instrumentos convencionales para la tutela de los derechos del hombre.

Sin embargo, si acogemos el concepto de cultura de los derechos humanos, como aquel utilizado por el profesor Longo que afirma: "Hablar de cultura de los derechos humanos significa hacer referencia aquella operación cultural a través de la cual los derechos se traducen en valores, normas, actitudes, orientaciones que inspiran los comportamientos de las personas consideradas singularmente o colectivamente, en una palabra, un sistema cultural de referencia complejo" (DI CRISTOFARO LONGO, 2002, p. 46) estamos lejos de presenciar esta operación "cultural", dado el abismo existente entre los niveles declaratorios de los derechos y de realización de los mismos, que se traduzcan en experiencias comunes constantes y en un aprendizaje de individuos y comunidades.

Esto ha originado que muchos derechos humanos, para algunas realidades culturales, constituyan mitos de la cultura occidental, conceptos vacíos 
y distantes de la vivencia cotidiana de individuos y pueblos. No existe correspondencia entre la elaboración sistemática de los derechos por parte de los Estados en los niveles normativos nacional e internacional (lógica estatal) y las orientaciones culturales y de comportamientos de individuos y grupos. Se vive una realidad de "suspensión cultural' como afirma el profesor italiano Longo, llena de paradojas, como aquella que acepta la validez de los derechos como cultura mundial de referencia pero al mismo tiempo acepta con resignación su precaria realización.

Por otra parte, sabemos la relación estrecha entre cultura y derecho. La cultura crea el derecho y viceversa, el derecho es la misma expresión de la cultura o del espíritu de los pueblos (volksgeist) como afirmara Carlo von Savigny, fundador de la Escuela Histórica del Derecho. Y con Savigny recordamos que el derecho es propio de cada pueblo, como el lenguaje, las costumbres y la organización política.

Los recientes desarrollos en derechos humanos traslucen prácticas comunes de los Estados nacionales, como se ha indicado, donde se evidencia el multiplicarse de instrumentos de tutela de los mismos, sin que sirvan de obstáculo las diversas tradiciones y contextos culturales en los cuales se asimilan. Prueba de ello es la expansión de los derechos humanos en las áreas del Islam, en los espacios árabe y asiático. Veamos estos acontecimientos.

\section{El area declaratoria de las democracias occidentales}

En esta área se individualizan dos espacios de los derechos humanos, el espacio europeo y el latinoamericano. Estructuralmente, los dos espacios tienen la misma matriz filosófica, en cuanto el iusnaturalismo y el iluminismo europeo florecido entre los siglos XVI y XVIII, fue adquirido y desarrollado con sus propias particularidades, desde el pensamiento iluminista latinoamericano, que representó el fermento para las luchas independentistas de las colonias españolas y llevó hasta la formación de las nuevas repúblicas latinoamericanas en el siglo XIX.

\section{El espacio Europeo}

El desarrollo del actual y complejo catálogo de los derechos humanos en el espacio europeo tuvo tres grandes impulsos vitales, los cuales, luego de las reformas a los principales tratados comunitarios (de la Unión europea), se 
sumaron en dar vida a lo que la doctrina denomina "los principios generales del derecho comunitario".

En este sentido, son tres las fuentes del reciente catálogo de derechos fundamentales en este espacio, es decir:

- Los derechos desarrollados por parte del Consejo de Europa ${ }^{2}$, principalmente con la Convención Europea de Salvaguardia de los Derechos del Hombre y de las Libertades Fundamentales (CEDU) y sus diferentes protocolos adicionales ${ }^{3}$, junto a los protocolos previstos en los diferentes tratados sobre los derechos humanos ${ }^{4} \mathrm{y}$ a los protocolos emanados por el Tribunal Europeo de los Derechos Humanos, mejor conocidos como la jurisprudencia o doctrina de Estrasburgo.

- Los derechos propios de las tradiciones constitucionales de los paises miembros de la Unión.

- Los derechos afirmados por los tratados comunitarios.

Como puntos de reflexión preliminares, es importante destacar que el sistema europeo de los derechos humanos se inspira, desde el principio, hasta la Declaración Universal de los Derechos del Hombre del 1948, representando una tarea de los Estados en la actuación de los principios contenidos en ese

\footnotetext{
${ }^{2}$ Cfr. De Salvia, (1999, p. 20), Es una organización intergubernamental instituida con el objetivo de lograr una Unión siempre más estrecha entre sus miembros, mediante la reafirmación de los principios de democracia, del estado de derecho y del respeto de los derechos humanos. Actualmente está formada por 46 Estados. De conformidad con De Salvia, el Consejo se ha fijado un dúplice objetivo: a.- salvaguardar los derechos y las libertades de las personas en los Estados miembros; b.- desarrollar tales derechos y libertades, ampliando los contenidos e incorporándolos en los textos normativos vinculantes. Estos objetivos se deducen del tercer considerando del preámbulo de la CEDU, que afirma: "Considerando que el fin del Consejo de Europa es aquel de realizar una unión más estrecha entre sus miembros, y que uno de los medios para conseguir tal fin es la salvaguarda y el desarrollo de los Derechos Humanos y de las Libertades fundamentales".

${ }^{3}$ Los protocolos adjuntos del CEDU son: el protocolo adjunto n. 1, firmado en París, el 20 de marzo de 1952; el protocolo n. 4, firmado en Estrasburgo, el 16 de noviembre de 1963, el protocolo n. 6, firmado en Estrasburgo, el 28 de abril de 1983, y el protocolo n. 7, firmado en Estrasburgo, el 22 de noviembre de 1984. El protocolo n. 11 ha introducido una modificación sustancial en el sistema de protección, reemplazando los dos órganos jurisdiccionales inicialmente previstos por la CEDU del 1950, es decir, la Comisión y la Corte europea de los Derechos Humanos, con un único órgano: la Corte Europea de los Derechos Humanos.

${ }^{4}$ A la fecha actual, el Consejo de Europa ha suscrito numerosos tratados (actualmente más de 190). Entre los más relevantes destacan: la Carta Social europea, suscrita en Turín el 18 de octubre de 1961 que entró en vigor el 26 de febrero de 1965; la Convención contra la Tortura, suscrita el 26 de noviembre de 1987 con entrada en vigor el 1 de febrero de 1989; la Convención sobre la Protección de las Minorías Nacionales, del 01 de febrero de 1995, entrando en vigor el 1 de febrero de 1998; la Convención sobre Derechos Humanos y la Biomedicina, del 04 de abril de 1997, entrando en vigor el 1 de diciembre de 1999.
} 
documento así como el asegurar la garantía colectiva de esos derechos, a través de la institucionalización de los propios órganos de protección.

Por otro lado, el modelo de los derechos presente en la CEDU obedece principalmente a la tradición democrático-liberal del Occidente, con una preeminencia de los derechos civiles y políticos. Los demás derechos, los sociales, económicos y culturales, que tuvieron un tratamiento marginal en el texto del 1950, han adquirido un mayor desarrollo a través de la Carta Social Europea del 1961 y de sus protocolos adicionales ${ }^{5}$ y las demás Convenciones del Consejo de Europa en la materia.

A pesar de este modelo inicial, el catálogo de los derechos fundamentales europeos se ha extendido a través de la interpretación progresiva y dinámica de los derechos por parte de la Corte Europea, que "ha contribuido a la formación de un concreto derecho constitucional europeo en materia de derechos fundamentales" (DE SALVIA, 1999, p. 29).

En este proceso de completación del elenco de los derechos, no ha influido únicamente la Corte Europea come antes indicado, sino también los diferentes organismos comunitarios, a partir del Tratado de Maastricht, que se han empeñado en la tutela de los derechos.

Cabe destacar en este último proceso de extensión y reforzamiento de los derechos, y en general del sistema de protección, los siguientes aspectos a considerar:

- una mayor conciencia de los derechos humanos por parte de los representantes gubernamentales y de la sociedad civil europea;

- los derechos humanos constituyen un elemento de la legitimidad democrática de los países miembros de la Unión;

- los derechos humanos se introducen en el más amplio proceso general de integración europea, actualmente en desarrollo y consolidación.

A nivel declaratorio, destaca la reciente "Carta de los Derechos y de las

\footnotetext{
${ }^{5}$ La Carta social europea ha experimentado una revisión general, aprobada el 3 de mayo de 1996, entrando en vigor el 1 de julio de 1999, y sus protocolos adjuntos son: n. 1, suscrito el 05 de mayo de 1988, entrando en vigor el 4 de septiembre de 1992; y el protocolo del sistema de recursos colectivos, del 9 noviembre de 1995, entrando en vigor el 1 de julio de 1998.
} 
Libertades fundamentales del la Unión Europea", mejor conocida como "Carta de Niza", emanada por el Parlamento, en su reunión del 2 de octubre 2000, carta que, aunque no tenga un pacífico reconocimiento en su validez jurídica, constituye un importante documento ético-político de la Unión. La Carta tuvo como fundamento y justificación la necesidad de integración y de consolidación en un texto único del corpus iuris de los derechos fundamentales de la Unión dispersos en la CEDU, en los diferentes tratados comunitarios e internacionales, tomando en cuenta la insuficiencia y complejidad de la regulación comunitaria.

\section{El espacio latinoamericano}

La conciencia de los derechos humanos en la región ha sido presente no sólo desde el inicio del desarrollo del derecho internacional de los derechos humanos a partir de la segunda mitad del siglo XX, sino que ha representado una conciencia radicada en la origen de la formación de las nuevas repúblicas, por parte de las élites revolucionarias y del pensamiento iluminista y humanista de los intelectuales latinoamericanos.

Ejemplos significativos de las contribuciones de los intelectuales iluministas son el pensamiento de Andrés Bello y de Antonio Nariño, que expresaban la centralidad de la educación como instrumento para la emancipación humana y como condición para el desarrollo de la sociedad civil y de la política, que pudiese permitir al hombre una mejor selección de su destino.

Entre otros, destaca el pensamiento filosófico y emancipador de Simón Bolívar, que fue capaz, no solamente de guiar las revoluciones independentistas del Venezuela, de Colombia, Perù, Ecuador y Bolivia, sino también de dar una altísima contribución a la "filosofía humanista latinoamericana", por haber sido capaz de luchar por algunas reivindicaciones que para su época podían considerarse utópicas, como la lucha en contra de la esclavitud (emblemático fue lo afirmado: "la violación de todas las leyes es la esclavitud") y la defensa de la dignidad de los indígenas.

Es importante recordar entonces, que la gran parte de los Estados latinoamericanos nacen bajo la influencia del liberalismo político, del pensamiento iluminista europeo y del pensamiento independentista norteamericano, llevando en el embrión constitucional esos principios 
propios de las cartas constitucionales europeas del siglo XVIII' ${ }^{6}$.

A partir de la segunda mitad del siglo XX, comienza una etapa fundamental en la formación y consolidación del sistema interamericano de tutela de los derechos. En este período, se instaura una nueva fase histórica en América Latina, con cambios esenciales en las condiciones jurídicas y políticas, dada la ampliación del horizonte constitucional de los Estados latinoamericanos. Esta expansión fue posible con la introducción de la democracia y la formación del Estado del bienestar, bajo la influencia de la ideología del Estado Social europeo y del modelo del Welfare State experimentado en Norteamérica, desarrollado a partir del modelo económico keynesiano.

La última parte de los años 40’ signa el ingreso de América Latina en el sistema de tutela de los derechos del hombre. Este sistema está conformado por el conjunto de organismos para la tutela y promoción de los derechos humanos en la región.

La formación de ese sistema interamericano fue posible por las siguientes razones, entre las más importantes:

- la necesidad de consolidar la democracia y la libertad en los Estados latinoamericanos;

- la necesidad de crear mecanismos de prevención contra las amenazas a los derechos humanos en la región;

- la creciente conciencia en proteger los intereses y las necesidades de los países latinoamericanos en el foro internacional;

- el intento por frenar la política de intervención y hegemonía de los Estados Unidos en la región.

Además, la edificación del sistema interamericano implicó dos condiciones esenciales: por un lado, la toma de conciencia de los Estados latinoamericanos de la necesidad de participar con un rol activo a la defensa y promoción de los derechos del hombre, también en la conciencia de lograr una mayor legitimidad por parte de los gobiernos; y por el otro, el desarrollo paralelo del sistema internacional de tutela de los derechos del hombre en las Naciones Unidas.

En el seno de la novena Conferencia Internacional Americana, en abril

\footnotetext{
${ }^{6}$ La primera Carta Constitucional de la República de Venezuela, del 1811, preveía algunas garantías judiciales. La institución de "amparo constitucional" aparece por primera vez en la Constitución Federal mexicana del 1857, con la finalidad de constituir un recurso de revisión de la constitucionalidad de las leyes en casos concretos que lesionaran los derechos constitucionales.
} 
de 1948, en Bogotà, Colombia, fue aprobada, junto con el Tratado o Carta de Bogotà que introdujo la Organización de los Estados Americanos (OEA), la "Declaración Americana de los Derechos del Hombre". En este documento, los Estados latinoamericanos afirmaron solemnemente la centralidad de la protección internacional de los derechos del hombre como principio guía del derecho americano ${ }^{7}$.

Además, en la Cumbre Especializada Interamericana sobre los Derechos Humanos, en San José de Costa Rica, el 22 de noviembre 1969, fue aprobada la Convención Americana de los Derechos, instrumento convencional que establece las obligaciones entre los Estados en materia fundamentalmente de derechos civiles y políticos, que dio vida a la Corte Interamericana de los Derechos, en calidad de órgano jurídico encargado de la vigilancia del cumplimiento de ellos.

\section{Area declaratoria del Islam}

La tradición de los derechos humanos, tal como ha sido desarrollada en las áreas de las Democracias Occidentales, presenta algunos aspectos característicos en el Islam, que, aún siendo diferentes en cuanto al origen e interpretación de los derechos, muestra puntos de convergencia con la tradición propia del occidente. Decir que los derechos humanos, en su perfil histórico, nacen en occidente, no significa descuidar el hecho que la irrupción de los derechos, especialmente con la expansión de la democracia y el desarrollo del derecho internacional de los derechos humanos, no haya tenido, y siga teniendo, una recepción o impacto sobre el derecho islámico, en su tradición jurídica además que en la opinión publica ${ }^{8}$, representativa en esta área.

Y muestra de ello es la emanación de las diferentes cartas de los derechos del hombre en los espacios del Islam, la adhesión por parte de muchos Estados islámicos de los diferentes instrumentos internacionales en defensa de los

\footnotetext{
${ }^{7}$ Así lo establece el tercer considerando de la Resolución XXX de la IX Conferencia Interamericana sobre la Declaración Americana de los Derechos Humanos. Es de resaltar que la Declaración Americana precede en más de seis meses a la Declaración Universal de los Derechos Humanos de las Naciones Unidas. En esa misma Conferencia fueron aprobadas la "Convención sobre la concesión de los derechos civiles y políticos de la mujer", la "Carta Internacional Americana sobre Garantías Sociales" y la "Condición Económica de la Mujer Trabajadora".

${ }^{8}$ El estudioso Salvatore Armando, en su artículo Movimenti islamici, idea dello pubblico e il nodo della società civile, analiza en profundidad el discurso islámico público y destaca el "efecto Habermas" en la esfera pública de los países islámicos, en los cuales se desarrolla una mayor y creciente reflexión crítica racional sobre argumentos como la religión en los jóvenes, la redefinición del sujeto y la legitimidad de la comunidad política, así como de las virtudes republicanas, a semejanza de las concepciones occidentales de las esferas públicas, en http://dexl.tsd.unifi.it/ig/es/index.htm?surveys/ islam/
} 
derechos humanos ${ }^{9}$, la inclusión de los derechos en algunos preámbulos y constituciones de los Estados islámicos ${ }^{10}$, el surgimiento de movimientos y asociaciones en defensa de los derechos ${ }^{11}$, el debate entre las élites intelectuales y espirituales y las organizaciones intergubernamentales, la sociedad civil, los jefes de Estados y hombres de política, entre otros. Sin embargo, el ingreso de la cultura de los derechos humanos en el Islam, ha sido marcado por un camino lento y difícil ${ }^{12}$.

Entre los factores que han obstaculizado este pasaje (no sabemos cuanto inevitable), podemos identificar los siguientes:

- el surgimiento de movimientos fundamentalistas ${ }^{13}$ en el siglo XX, que han instrumentalizado, y siguen haciéndolo, la religión y subvierten los valores de la tradición de la civilización islámica.

- El desconocimiento por parte del Occidente de la genuina tradición islámica.

Por otro lado, la interpretación de la Sharia, basada en la genuina

\footnotetext{
${ }^{9}$ Países como Afganistán e Irán han ratificado el Pacto sobre los Derechos Civiles y Políticos así como el Pacto sobre Derechos Económicos, Sociales y Culturales.

${ }^{10}$ Como afirma Ceccanti (2003), en los textos constitucionales de Algeria, Bahrain, Egipto, Jordán, Marruecos, Túnez, Mauritania y Yemen, prevalecen las adaptaciones pragmáticas entre tradición islámica y occidental. Por ejemplo, la Constitución de Algeria reconoce la inviolabilidad de la libertad de conciencia y de opinión en su artículo 36. El preámbulo de la Constitución de Mauritania inicia con las siguientes palabras "Confiando en la omnipotencia de Dios" y continúa con la proclamación de la fidelidad al Islam, a la democracia, a la Declaración Universal del 1948 y a la Carta Africana de los Derechos Humanos y de los Pueblos del 1981. La Constitución del Irán afirma que la mujer "debe reconquistar su verdadera identidad y los derechos humanos”. El preámbulo de la Constitución del Líbano, definido como un Estado laico, hace referencia expresa a la Declaración de las Naciones Unidas del 1948 y el artículo ${ }^{9}$ del texto constitucional proclama la libertad religiosa. Para una mayor profundización, ver S. Ceccanti. Religione, diritti e garanzie nei Paesi arabi, en Quaderni di Diritto e Política Ecclesiastica, No. 1, Studi/Interventi/Dibattiti, Milán, abril 2003.

${ }^{11}$ Entre los más relevantes, se encuentran la Liga Tunecina de los Derechos Humanos (creada en el 1976), la cual diseñó la Carta de los Derechos Humanos (1985), la Liga Egipciana de los Derechos Humanos (1985), la liga de los países magrebinos, por ejemplo, la Liga "Collectif 95 Maghreb Egalite" que agrupa tres organizaciones femeninas de Algeria, Marruecos ("Rights of the Muslim Women") y Túnez (Comitè pur le respect des libertès et des droits de l'homme). Todos estos actores sociales promueven, al interno del movimiento internacional de los derechos que agrupa todas estas organizaciones, el reconocimiento de los valores y de los derechos previstos en la Declaración Universal del 1948 por parte de los Estados islámicos.

${ }^{12}$ Se recuerda en esta sede la abstención de Arabia Saudita en el proceso de aprobación de la Declaración Universal de los Derechos Humanos del 1948.

${ }^{13}$ Como indica el prof. Ahmad 'Abd Al-Waliyy (2001, p. 184) los exponentes de la Iglesia Baptista Americana (191012) utilizaron por primera vez el término "fundamentalismo", dando nombre a una ideología que se había delineado en el curso del XIX siglo, en ámbito positivista, siendo además difundida en el mundo islámico, a través de la acción propagandística de personajes como a-Afghani (1838-1897), Muhamad 'Abduhu (1849-1905), Rashid Rida (1865-1935), ligados a las ideologías políticas modernas.
} 
tradición islámica (AHMAD 'ABD AL-WALIYY, 2001, p. 177), evidencia que los valores por excelencia del patrimonio jurídico de las Democracias Occidentales, como la libertad, igualdad, tolerancia, el pluralismo religioso y la solidariedad, no son extraños a la civilización islámica, del mismo modo, están a la base de la creación del universo jurídico islámico. De la misma forma, estos valores pertenecen a la reflexión ético-jurídica y al desarrollo en el curso de los siglos de la Sharia ${ }^{14}$ así como al debate actual. Todo esto ha sido destacado por intelectuales como V. Ahmad 'Abd Al-Waliyy Ahmad y Abdullah Ahmed An-Na'im.

\section{El espacio Arabe}

La toma de conciencia de los Estados árabes respecto a la necesidad de adecuar sus ordenamientos jurídicos en conformidad con el derecho internacional, se manifiesta al final de los años 70'. A partir de esa fecha, el área árabe-musulmana ha elaborado diferentes declaraciones de los derechos humanos ${ }^{15}$, entre otras:

Las Declaraciones de los Derechos Humanos de la Organización de la Conferencia Islámica ${ }^{16}$ del 1979, 1981 e del 1990 (esta última conocida con el nombre de "Declaración del Cairo sobre los Derechos del Hombre en el Islam”, Resolución No. 49/19-P).

- La Carta árabe de los Derechos Humanos, adoptada a partir del 15-09-

\footnotetext{
${ }^{14}$ Mientras el Corán ha sido recopilado inmediatamente después de la muerte del Profeta Mahoma, la recopilación de la Sunna empleó casi dos siglos. Como indica el prof. V. Ahmad 'Abd Al-Waliyy (2001) "la rápida expansión del Islam habría comportado el hecho que muchos de los compañeros del Profeta se habrían dispersos en nuevos territorios islámicos y con ello el patrimonio de tradiciones que habían memorizado durante los años pasados con Mahoma. Muy pronto entonces comenzaron a circular en la ciudad del mundo islámico las primeras recolecciones de tradiciones y la búsqueda de las tradiciones proféticas habría asumido un puesto de relieve al interno de la más general «búsqueda del conocimiento..." Una de las más fidedignas recopilaciones de las tradiciones proféticas (hadith) y de las opiniones jurídicas ha sido realizada por el fundador de la escuela Malikita, Malik Ibn Anas, intitulada "AlMuwatta." Esta recopilación constituye el documento jurídico más antiguo del Islam y ha sido además el modelo para las futuras recopilaciones de las tradiciones. En la actualidad, no existe una opinión unitaria y pacífica sobre cuáles hadith son confiables, por ejemplo una colección de hadith del IX siglo indica 300.000, de los cuales sólo 8000 son considerados auténticos.

${ }^{15}$ En el cuadro de las Declaraciones sobre Derechos Humanos, se debe también tomar en consideración aquellas emanadas del Consejo Islámico del 1980 y del 1981, así como las recomendaciones de la Convención del Kuwait de 1980. Para una mayor profundización ver Aldeeb Abu-Sahlieh (1994; 1997, p. 473).

${ }^{16}$ La organización de la Conferencia Islámica es una organización intergubernamental compuesta por 56 países árabes, que tienen entre los objetivos más importantes aquellos de la solidaridad y cooperación entre los países árabes, la lucha contra el colonialismo, el racismo y la promoción de la paz internacional.
} 
1994, en el Consejo de la Liga de los Estados Árabes, Resolución No. 5437.

La primera declaración de la Organización de la Conferencia Islámica que comprende todos los países musulmanes, fue aprobada en el año 1979.

La "Declaración Universal Islámica sobre los derechos Humanos" del 19 septiembre del 1981, ha sido elaborada por el Consejo de la Organización de la Conferencia Islámica y redactada por juristas islámicos y por representantes de las diferentes escuelas de pensamiento islámico, bajo la aprobación de la Unesco.

Esta carta de los derechos, en su preámbulo, afirma tener sus raíces en el Corán y en la Sunna, es decir, en las dos raíces o fuentes principales del derecho islámico. Al mismo tiempo, la Carta establece el fundamento teológico de los derechos, a través del principio que los derechos humanos surgen por una fuente divina, es decir, por "Dios" en su rol de supremo legislador.

Por otro lado, los derechos humanos se integran en el marco complejo del ordenamiento jurídico islámico, proclamando las libertades tradicionales liberales. Igualmente la Carta islámica reconoce los derechos sociales y económicos, además de algunos derechos colectivos como el derecho de las minorías religiosas, individuando expresamente el pluralismo religioso.

A pesar de la enunciación solemne de los derechos, todos éstos reconducen a la sharia en cuanto a su interpretación y aplicación. En la declaración islámica, la ley es definida como la "totalidad de las normas provenientes por el Corán y por la Sunna, y por las demás leyes que tienen raiz en estas dos fuentes a través de los métodos considerados válidos según la jurisprudencia islámica ${ }^{17}$ ".

La "Declaración del Cairo de los Derechos del Hombre en el Islam", elaborada en el marco de la Organización de la Conferencia Islámica, ha sido adoptada en el 1990 en la XIX Conferencia de los Ministros Exteriores. No obstante, todavía no ha sido aprobada por la Conferencia de los Reyes y de los Jefes de Estado y de Gobierno, que representa el principal ente político del la OCI.

Con relación al contenido de esta declaración, se reafirma el discurso teológico-jurídico iniciado en el curso de la Declaración Islámica Universal del 1981, en el sentido de colocar los derechos humanos en el marco complejo

\footnotetext{
${ }^{17}$ Ver el preámbulo de la "Declaración Universal Islámica sobre Derechos Humanos", las notas explicativas n. 1. Del mismo modo, puntualiza la Carta que el término "Law" indica expresamente Sharia.
} 
del Islam ${ }^{18}$. De esta forma, Dios es el legislador y la suprema fuente de los derechos, las personas son criaturas de la Divinidad, la vida es un don divino y todos los derechos humanos deben ser interpretados y aplicados según la Sharia ${ }^{19}$.

El actual debate en torno a los derechos humanos puede ser interpretado a través de tres direcciones (ALDEEB ABU-SAHLIEH, 1997, p. 468):

- Corriente Islamista: pretende liberarse de las normas occidentales para aplicar únicamente las normas islámicas. Corresponde a los diferentes modelos constitucionales elaborados por los islamistas, por ejemplo, el Partido de Liberación, de Garishah y de Wasfi. Esta tendencia está presente en Egipto. (Hermanos Musulmanes).

- Corriente Secular: defiende la eliminación de las normas islámicas vigentes, sobre todo esas normas que se refieren al derecho de la familia, en cuanto a su carácter discriminatorio respecto a la mujer y a los no-musulmanes. Esta corriente está integrada por la organización "Collectif 95 Maghreb Egalite" que incluye las tres organizaciones feministas de Marruecos y Tunés, con su proyecto de Ley "100 Resoluciones y disposiciones para una codificación maghrebina igualitaria de los derechos de la personalidad y del derecho de la familia".

- Corriente Positivista: reúne los movimientos islámicos moderados, que reconocen y quieren aplicar la ley islámica en conformidad con los derechos humanos y defienden la aplicación de la ley positiva fijada por el Estado. En este sentido, no niegan su tradición y tampoco rechazan su enlace con la tradición occidental de los derechos. Además, reivindican un sistema jurídico adecuado a las necesidades de la sociedad (función social del derecho) y creen que así hay que proponer la interpretación del

\footnotetext{
${ }^{18}$ Ver el preámbulo de la Declaración, cuarto parágrafo, "Believing that fundamental rights and universal freedoms in Islam are an integral part of the Islamic religion and that no one as a matter of principle has the right to suspend them in whole or in part or violate or ignore them in as much as they are binding divine commandments, which are contained in the Revealed Books of God and were sent through the last of His Prophets to complete the preceding divine messages thereby making their observance and act of worship and their neglect or violation an abominable sin, and accordingly every person is individual responsible - and the Ummah collectively responsible - for their safeguard".

${ }^{19}$ Así lo indican expresamente los artículos 24 y 25 de la Declaración: Article 24: All the rights and freedom stipulated in this Declaration are subject to the Islamic Shariah. Article 25: The Islamic Sharia is the only source of reference for the explanation or clarification of any of the articles of this Declaration.
} 
Corán y de la Sunna. Ellos afirman que los suras del Corán y las tradiciones de Mahoma son generalmente incompletos, manipulados y extrapolados por el contexto, además que inadecuadamente interpretados. Por estas razones, no rechazan la legislación extranjera. También esta tendencia está presente en Egipto.

Todas estas declaraciones destacan la convergencia de la tradición de los derechos desarrollada en las áreas de las Democracias Occidentales en el Islam. Ellas pueden ser interpretadas como intentos de convergencia entre tradición occidental y tradición islámica, en clave política.

En este sentido, las declaraciones de los derechos humanos, aunque no tengan una valor jurídico, representan una forma de salvoconducto éticopolítico en la proyección de las sociedades islámicas hacia el Occidente, para su reconocimiento. Por otro lado, la intención de institucionalizar un sistema regional de tutela de los derechos en el espacio árabe, parece obedecer sobre todo a las razones de Estado, es decir, a la búsqueda de legitimidad política por parte de los Estados árabes, especialmente en el marco internacional. Además, hay signos que muestran la debilidad del proceso de integración de los derechos humanos en el complejo marco del Islam, como, por ejemplo, el hecho que la mayoría de los Estados todavía no hayan ratificado la Carta Árabe de los Derechos Humanos.

Actualmente, la realidad jurídica de estos países es compleja y no armonizada. Aunque gran parte de la legislación de estos países comparta formalmente la visión "moderna" de los derechos en los preámbulos y en las cartas constitucionales (BORRMANS, 2000, p. 89) es evidente su "distancia" desde el tejido social, es decir, su ausencia en clave cultural ${ }^{20}$.

Por otro lado, uno de los aspectos de tensión en la convergencia entre el Islam y la tradición de los derechos humanos de las Democracias Occidentales, destacado por la reciente doctrina, es el sistema educativo, como ha sido detalladamente analizado por el Instituto Árabe de los derechos humanos. El estudio avanzado por este centro de investigación intitulado "La educación y los derechos del hombre" revela que, aunque los Estados árabes hayan adherido

\footnotetext{
${ }^{20}$ El antropólogo Rouland (1998, p. 276) advierte esta falta de integración de los derechos, a propósito de la instrumentalización hecha por las elites intelectuales islámicas de los derechos humanos a favor de la lucha anticolonialista, dejando fuera del debate a la población civil.
} 
formalmente a los tratados internacionales de los derechos, los programas y los manuales escolares en esos países evidencian "enseñanzas contrarias a los derechos del hombre...los manuales enseñan y crean un ambiente islámico, mientras que la realidad cotidiana es otra" (BORRMANS, 2000, p. 89). En consecuencia, algunos autores persisten en la necesidad de armonizar la legislación y los programas de educación de los países islámicos a la cultura de los derechos humanos.

Todosestos puntos detensión revelan, por un lado lainsuficienteintegración de los derechos entre tradición islámica y occidental, la cual queda como un saludo a la bandera, como parte del protocolo y de los rituales modernos de la diplomacia, y por el otro la necesidad del diálogo y de la confrontación intercultural, capaz de meter las bases para la comprensión de las virtudes y de los límites de ambas tradiciones, a partir de un conocimiento integral de ellas. Para cumplir con este trabajo es necesario descartar las posiciones de oposición de las dos tradiciones, es decir, la globalización de los derechos humanos y la corriente islámica, puesto que ambos representan las diferentes caras del mismo fenómeno que pone una cultura en conflicto con la otra, por estimarla superior, provocando la exclusión de la otra. Con respeto a las tendencias sobre los derechos humanos, este antagonismo cultural es evidente en la corriente islámica y en la secular, ambas integralistas.

\section{El espacio africano}

En el marco de la XVIII Conferencia de los Jefes de Estado y de Gobierno de la Organización de la Unidad Africana, fue aprobada por unanimidad la Carta Africana de los Derechos de los Hombres y de los Pueblos, el 27 de junio 1981 en la ciudad de Nairobi, entrando en vigor en $1986^{21}$.

Además, durante los últimos treinta años, la dinámica políticosocial ha empujado en la región el surgimiento de un discreto proceso de sectorialización a cargo de la OUA, con la emanación de diferentes instrumentos internacionales para la tutela de los derechos humanos. Entre estos, hallamos la Convención Africana que regula los aspectos específicos de los problemas de los refugiados en África, aprobada el 19 de septiembre del

\footnotetext{
${ }^{21}$ La Carta es mejor conocida como "Carta de Banju", nombre de la ciudad del Gambia donde se realizaron las dos sesiones de la Conferencia de los Ministros de Justicia de la OUA, en la cual fue elaborado el proyecto definitivo. Hasta ahora, la Carta ha sido ratificada por 51 Estados de una totalidad de 53 Estados en todo el continente, excluidos Eritrea y Etiopía.
} 
1969 y en vigor a partir del 20 de junio del 1974 y la "Carta Africana de los Derechos del Bienestar del Niño”, aprobada en el mes de julio del 1990.

\section{La carta africana de los derechos humanos y de los pueblos}

Este instrumento sigue la orientación de la Convención Europea y Americana, es decir, del reconocimiento de los derechos que conforman los dos grandes sistemas materiales e históricos. Además, en el preámbulo se declara la interdependencia de estos sistemas. En la Carta africana se proclama un número discreto de derechos civiles y políticos fundamentales de la tradición liberal, junto con algunas garantías procesales, así como algunos derechos económicos, sociales y culturales ${ }^{22}$.

Entre los derechos sociales, destaca la atención dada a la familia, que es considerada como "el custodio de los valores y de las tradiciones comunitarias" (art. 18), el énfasis dada a la prohibición de discriminar la mujer y el niño (art. 18), así como el deber del Estado de promover y proteger las tradiciones y la moral de las comunidades africanas (art. 17).

Son interesantes igualmente las diferentes disposiciones dedicadas a la defensa de los valores y de la tradición histórica y cultural de las comunidades africanas, expresamente proclamada en el preámbulo de la Carta y en los artículos 17, 18, 22 e 29.

La particularidades de esta Convención, en relación a las homologas de otros espacios, es la proclamación de un grupo numeroso de derechos de los pueblos, entre ellos, el derecho a la existencia y a la autodeterminación (art. 20), a la asistencia por parte de los Estados africanos en la lucha por la independencia (art. 20), a la libre disponibilidad de los recursos económicos y culturales (art. 21), al desarrollo cultural, económico y social (art. 22), a la paz, seguridad nacional e internacional (art. 23) y a un ambiente favorable al desarrollo (art. 24).

La afirmación de los derechos de los pueblos evidencia la pretensión de los Estados africanos de reafirmar la propia identidad como países independientes, a prevenir cualquier tipo de sumisión por parte de otros países, así como su necesidad de lograr una mayor autonomía, especialmente política y económica.

${ }^{22}$ Los derechos están previstos en la primera parte de la Convención, intitulada "De los Derechos y Deberes", capítulo I. 
Otra distinción que hace particular esta Convención es el largo elenco de los deberes ${ }^{23}$ y entre éstos, los deberes hacia la familia, como la preservación armoniosa de su desarrollo, la solidariedad entre los individuos, la tolerancia, los servicios a la comunidad nacional, la preservación y la defensa de la independencia nacional, la promoción de la unidad africana así como la preservación de los valores culturales positivos africanos.

\section{El espacio asiático}

A diferencia de los demás espacios analizados en esta sede, en el espacio asiático, no se han instaurado todavía mecanismos regionales de protección de los derechos humanos, aunque hay en acto iniciativas para su promoción ${ }^{24}$.

Por otro lado, en este espacio no hay declaraciones solemnes sobre los derechos humanos, aunque los Estados asiáticos hayan adherido a los principios de la Carta de las Naciones Unidas y de la Declaración Universal del 1948, según la proclamación hecha en la Declaración de Bangkok del 1993.

Tomando en cuenta la tradición ética induista, India muestra una perspectiva cósmica con respeto a los derechos del Hombre (ROULAND, 1998, p. 270).

Según el antropólogo Rouland, el sistema induista está fundamentado en la idea de la relativización de los derechos, en función del lugar ocupado por cada uno en la sociedad, como en el universo. Para entender esta afirmación, es importante puntualizar algunas premisas del derecho en su articulación en la tradición indiana que puedan ser útiles para una mayor inteligencia del argumento.

\section{El Dharma o "propósito en la vida"}

Este es un concepto un central en la tradición indiana. Se trata de una

\footnotetext{
${ }^{23}$ Previstos en los artículos 27 al 29, en la primera parte de la Convención, relativa a los "Derechos y Deberes", Capítulo II.

${ }^{24}$ Ver la "Carta Asiática de los Derechos Humanos", aprobada en ocasión de la celebración del 50' aniversario de la Declaración Universal de los Derechos Humanos del 1948, en Kwanglu, Corea del Sur, el 17 de mayo 1998. Este documento representa el producto de un trabajo de intensa participación popular, más de 200 organizaciones no gubernamentales del Asia intercambiaron ideas y diseñaron el proyecto de Declaración, en un tiempo de tres años. La versión final de la Carta ha sido a cargo del Prof. Yash Ghai, bajo la dirección de un comité de intelectuales honorables de los pueblos asiáticos y representantes de la Comisión Asiática de los Derechos Humanos. El texto de la carta asiática se encuentra en la siguiente dirección electrónica: 〈http://www.hrni.org/files/instruments/HRNi_EN_1089.pdf〉.
} 
palabra que en sánscrito significa "propósito en la vida". Esta palabra tiene un significado muy profundo que permea todas las acciones humanas, las manifestaciones naturales, la creación, y por último, el orden entero del universo. "El dharma es cuanto da cohesión y fuerza a todo lo que existe" (ROULAND, 1998, p. 270). En consecuencia, el dharma se manifiesta en todas las dimensiones de la realidad, en la religión (entendido como lo que permite la Unión del universo), en la moral (a traves la armonía del ser), en la justicia (como lo que une los hombres) en la verdad (la cohesión interna de una cosa) (ROULAND, 1998, p. 270).

El hombre, cumpliendo con su deber, realiza su dharma. Esta es la vía, es decir, el camino que hay que seguir para la autorrealización espiritual. Cada hombre tiene la responsabilidad de hallar su armonía interior, con sus congéneres y con el universo. Es decir, debe esforzarse para realizar su dharma, a través del cumplimiento de sus deberes (que varían según la edad, el sexo y la condición social). Únicamente de esta forma, el hombre podrá lograr la armonía dentro de si, con los demás hombres y con el universo. El género humano tiene el "derecho de sobrevivir solo en la medida que cumpla con el deber de salvaguardar el mundo" (ROULAND, 1998, p. 271).

Bajo la perspectiva del dharma como derecho, se establece la primacía de los deberes sobre los derechos, en forma tal que los segundos no puedan existir si antes el hombre, con su acción, no se ponga en las condiciones de recibir su retribución al deber, en este caso, el derecho.

Además, el imperativismo propio de los derechos humanos como derechos subjetivos es extraño al dharma en cuanto como modelo comportamental es flexible y adaptable a modificaciones y derogaciones.

Bajo esta perspectiva, para lograr la armonía del universo, los derechos no pueden corresponder sólo al hombre, sino a todas las criaturas, incluidos los animales, los vegetales, las criaturas inanimadas y también los dioses. En este sentido, "el hombre es sólo una abstracción, en cuanto no existe fuera de las relaciones que lo atan a todas estos componentes de la realidad." (ROULAND, 1998, p. 271).

En la constitución indiana se refleja este enfoque general de los derechos humanos, sobre todo en el capítulo referido a los deberes de los ciudadanos. El artículo 51 de la Constitución indiana prevé el deber de los ciudadanos indianos de "e) promover la armonía y el espiritu de común hermandad entre 
todos los indianos trascendiendo la diversidad religiosa, lingüistica y regional, renunciar a las practicas discriminatorias en contra de la dignidad del las mujeres... g) promover y mejorar el ambiente natural ... y tener compasión por las criaturas vivientes".

A pesar de la pretensión de armonía implícita en la noción de dharma, la sociedad induista ha sido criticada, a la luz de la tradición occidental, a causa de la existencia de la paria y de las castas, como una fuente de discriminaciones y desigualdades ${ }^{25}$.

El desarrollo del derecho internacional de los derechos humanos así como la modernización de los países asiáticos, ha llevado a numerosos debates en el área de los derechos humanos, sobre la democracia y la tradición liberaloccidental de los derechos.

Como resultado de este debate, que podemos declarar no definitivo ni terminado, se pueden identificar diferentes tendencias:

- Una corriente de pensamiento político de confrontación y oposición a la tradición de los derechos humanos de las Democracias Occidentales, llamada "Asian Values", llevada adelante por las elites políticas de los países, en particular por los llamados tigres asiáticos (Hong Kong, Singapur, Corea del Sur y Taiwán). Esta perspectiva tiene como fin reafirmar la identidad nacional de esos países, respecto a las fuerzas de la globalización y de la hegemonía occidental.

- Una corriente que declara la falsedad del debate de contraposición entre la tradición liberal-occidental de los derechos y tradición asiática, afirmando la existencia de una tradición de libertad en el espacio asiático, equivalente a la tradición occidental. Es la tesis sostenida por A. Sen y por los teóricos de la escuela noruego-holandesa de los estudios asiáticos.

La perspectiva del Asian Values se puede definir como una dirección teórica que se opone a la universalidad de los derechos humanos, en base al relativismo cultural, reivindicando la autonomía y la preeminencia de los valores tradicionales, históricos y culturales asiáticos respeto a los derechos promovidos por las Democracias Occidentales.

La problematicidad de la universalidad de los derechos humanos ha sido formulada a nivel de la comunidad internacional, principalmente en

${ }^{25}$ Las tres castas superiores de la India han sido los brahmanes, los guerreros y los artesanos. 
la Declaración de Bangkok, subscrita por un grupo de países asiáticos en un encuentro regional a Bangkok ${ }^{26}$, antes de la Conferencia Mundial de los Derechos Humanos celebrada en Viena en el 1993.

Sin embargo, como evidencian Bruun y Jacobsen, el concepto del Asian Values no es un fenómeno nuevo, en cuanto tiene sus precedentes en la historia colonial y post-colonial de los países asiáticos, en el debate chino sobre el "self-strengthening", en la ideología Pancasila de la Indonesia del post-guerra, en el sistema Panchayat en Nepal, en la política de democracia básica auspiciada por el Pakistán y en la reciente visión 2020 del Premier Mahathir.

No obstante, la declaración de Bangkok ha sido evaluada como inconsistente (BRUUN; JACOBSEN, 2000, p. 2) y con profundas contradicciones, porque, si por un lado acepta la universalidad de los derechos, por el otro reivindica la enorme importancia de las particularidades culturales y regionales, así como de los diferentes contextos históricos, religiosos y culturales del Asia ${ }^{27}$.

Partiendo de la base que hoy los derechos humanos están en fuerte expansión en Asia, algunos estudios consideran que esta tendencia, junto a su interés académico, deriva del hecho que representa una nueva dirección del viejo debate sobre el universalismo respecto al relativismo cultural y un consenso político que la retórica de los defensores del Asian Values han introducido en numerosos gobiernos asiáticos.

Bruun e Jacobsen concuerdan en afirmar que la perspectiva de los valores asiáticos es una clara respuesta de la necesidad creciente de las elites asiáticas de reafirmar su propia identidad nacional frente a las fuerzas de la modernización y de la globalización, fuera de su control. Por el otro lado, la globalización ha llevado a concebir el debate sobre los derechos humanos como una materia problemática que involucra al mundo entero.

En esta forma, no obstante el concepto de Asian values no refleje una común visión sobre los derechos humanos en Asia, manifiesta la necesidad compartida de desarrollar y reafirmar la propia identidad nacional (BRUUN;

\footnotetext{
${ }^{26}$ La reunión en Bangkok fue sostenida del 29 de marzo hasta el 2 de abril del 1993. Cuarenta y nueve Estados asiáticos prepararon la declaración.

${ }^{27}$ El párrafo 8 de la Declaración "reconoce que mientras los derechos humanos son universales por naturaleza, los mismos deben ser entendidos en el contexto de un proceso dinámico de fijación de los estándares internacionales de las normas, tomando en consideración el significado de las particularidades regionales y nacionales, además de las tradiciones históricas, culturales y religiosos".
} 
JACOBSEN, 2000, p. 13). Todas las argumentaciones presentadas por el Asian Values reflejan a juicio de Stokke, un sentido de paridad con el Occidente, incluso de superioridad frente a las disfuncionalidades de las sociedades occidentales (STOKKE, 2000, p. 139).

Amartya Sen, Premio Nobel de Economía, después de haber criticado la desconfianza del Asia en relación a los derechos humanos en su tradición occidental-liberal, así como la falsedad del debate de los valores asiáticos, reconstruye una corriente de pensamiento, de libertad y tolerancia de la tradición indiana.

Entre los argumentos expuestos, en primer lugar, advierte la imposibilidad de la existencia de una uniformidad de valores compartidos en el mundo asiático, por un lado, dada la inmensidad del espacio geográfico y por el otro, por la existencia de pueblos que viven diversas experiencias culturales y religiosas. En segundo lugar, defiende la paternidad no exclusiva del núcleo fundamental de los derechos de libertad por parte de Occidente y denuncia el hecho que ellos no han sido actuados en aquella área en forma milenaria. En este sentido, afirma que valores como la libertad y la tolerancia, han sido centrales en los debates de los intelectuales y de los políticos y pertenecen también a la experiencia cultural asiática. Además, la historia asiática revela la presencia de pensadores y políticos que promovían estos valores en la sociedad. Sen indica como ejemplos relevantes de la tradición hinduista, la doctrina del emperador Ashoka, (III anni a.c.) de defensa de la tolerancia de la diversidad, en una verdadera perspectiva universal. Al mismo tiempo, Sen señala el pensamiento del emperador mogul Akbar (1556-1605). No obstante este emperador no fuera un gobernador democrático, se caracterizó por haber reconocido diversos derechos humanos, entre ellos la libertad de religión, comprendidos el derecho de cambiar fe. La libertad religiosa era entendida como un deber del Estado y tenía que ser también virtud ciudadana.

Los investigadores del Instituto noruego-holandés de los estudios asiáticos, Bruun e Jacobsen, afirman que tanto los valores asiáticos como los valores de Occidente son construcciones modernas, como al mismo tiempo, los instrumentos internacionales de los derechos humanos (BRUUN; JACOBSEN, 2000, p. 9). A su juicio, el debate sobre la distinción y contraposición de estos dos modelos resulta falso y lleno de mitos, subrayando la necesidad de un enfoque adecuado para el análisis comparado de estos modelos. 
Para el profesor Stokke, no obstante este debate de contraposición haya sido enfocado en clave cultural, debe ser siempre interpretado en clave política, es decir, pertenece más a la naturaleza y a la esencia de la política y del rol del Estado en la sociedad, que a la esfera estrictamente cultural.

A esta línea de pensamiento, es relevante añadir la posición del constructivismo social. Este evidencia que tanto la cultura, el pensamiento y la religión, son objeto de instrumentalización por parte del sistema de poder y de privilegios, sirviéndose por otra parte, de esta condición, los más débiles como táctica defensiva.

Los autores de la escuela noruego-holandesa evidencian una tradición de las libertades en el área asiática, como ha sido indicado por Sen en la tradición indiana. La prueba de la existencia de esta tradición se afirma entre otros, por los siguientes motivos:

- El rechazo a la esclavitud y a la opresión pertenece a todos los pueblos, incluidos aquellos asiáticos.

- Los pueblos asiáticos participan plenamente en la modernidad global y al mismo tiempo a la paradoja de mayores libertades y disciplina. En este sentido, el proceso de modernidad global, caracterizado por un amplio nivel de racionalización (siguiendo Weber) y que regula las interacciones entre estado y sociedad, explica mejor el desarrollo de los diversos regímenes de los derechos humanos, que los mismos factores culturales (KELLY, 2000, p. 186).

\section{Conclusiones}

Como conclusiones a las premisas antes expuestas, podemos afirmar que:

- El espacio europeo coloca los derechos humanos en el cuadro complejo de los valores de la Unión Europea, come principios generales del derecho comunitario, de la integración económica-política y de la legitimación democrática. El espacio latinoamericano coloca los derechos humanos en el cuadro complejo de los objetivos de los Estados latinoamericanos en el propósito de alcanzar mayor autonomía y legitimidad democrática.

- El espacio árabe de los derechos refleja la pretensión de los Estados árabes de conseguir mayor legitimación en el foro de la comunidad 
internacional. El espacio africano coloca los derechos humanos dentro del cuadro complejo del proceso de descolonización y de consecución de mayor autonomía e identidad de los Estados africanos. El espacio asiático pone en evidencia la lucha por la constitución de una identidad nacional con los mismos instrumentos del Occidente, es decir, a partir de los derechos económicos.

Los resultados expuestos evidencian el predominio de la lógica estatal en la génesis de las recientes cartas, instrumentos y mecanismos de tutela de los derechos humanos, en detrimento de la vinculación necesaria entre la sociedad y el derecho, es decir, que éste último constituya el reconocimiento de valores reivindicados por los grupos sociales y fruto de una conciencia colectiva (cultura) en la escogencia de los modelos de vida en común. Asimismo, la hegemonía de esta lógica estatal dificulta el desarrollo de una cultura que se traduzca en una educación, especialmente, a través de la asunción y toma de valores, el desarrollo de actitudes y prácticas de los individuos y grupos en conformidad con los valores consagrados en las normas fundamentales.

Por otra parte, no podemos renunciar a proponer una nueva lectura de los derechos humanos en una perspectiva intercultural, que propicie el diálogo entre las diversas cosmovisiones y mitos de las culturas, en la cual tenga espacio el respeto recíproco y la igual dignidad de las culturas. Asimismo, el diálogo intercultural deberá propiciar nuevas formas de convivencia y de comunión de valores como la "solidaridad" así como una pedagogía de la alteridad. Se necesita rescatar la "antropología de la reciprocidad", recuperar la dimensión de la reciprocidad, es decir, de la convivencia de los diversos puntos de vista en su diversidad e interdependencia.

Se necesita de un proceso continuo donde los derechos sean levadura de objetivos que eleven la dignidad de los hombres y pueblos y que el goce de los derechos se transforme en experiencias cotidianas de hombres y mujeres, niños y niñas en el tiempo y en el espacio.

\section{Referencias Bibliográficas}

ALDEEB ABU-SAHLIEH. I movimenti dell'attivismo islámico, la Legge Islámica e i Diritti dell'Uomo. Rivista Internazionale dei Diritti dell'Uomo, Milano, Università Cattolica del Sacro Cuore, anno X, gennaio-aprile. 1997. 
ALDEEB ABU-SAHLIEH. Les musulmans face aux droits de l'homme. Winkler, Bochum, 1994.

AHMAD 'ABD AL-WALIYY, Vincenzo. Islam. l'altraciviltà. Mondatori: 2001.

BORRMANS, Maurici. Ipotesi di Convergenze sui Diritti dell'Uomo nel Mediterráneo. En: UNGARI, Paolo. Per una convergenza mediterranea sui Diritti dell'Uomo. Centro di Ricerca e di Studio sui diritti dell'uomo, Euroma, 2000.

BRUUN, Ole; JACOBSEN, Michael. Human rights and asian values. Contesting national identities and cultural representations in Asia. Richmond: Curzon, Nordic Institute of Asian Studies, 2000.

CAPOZZI, Gianluca. Forze, leggi e poteri, i sistemi dei diritti dell'uomo. Nápoles: Editorial Jovene, 1998.

CECCANTI, Stefano. Religione, diritti e garanzie nei paesi arabi. Quaderni di diritto e politica eclesiástica. Milán, Studi/Interventi/Dibattiti, n. 1, abril. 2003.

DE SALVIA, Michele. La convenzione europea dei diritti dell'uomo. Nápoles: Editoriale Scientifica, 1999.

DI CRISTOFARO LONGO, Giogia. I diritti umani. Dalla dichiarazione ai processi di inculturazione dei diritti umani. En: Per una cultura dei Diritti Umani. Milán: 2002.

KELLY, David. Freedom as an asian values. En: BRUUN, Ole; JACOBSEN, Michael. Human rights and asian values. Contesting national identities and cultural representations in Asia. Richmond: Curzon, Nordic Institute of Asian Studies, 2000.

ROULAND, Norbert. I fondamenti antropologici dei diritti dell'uomo. Rivista Internazionale di Filosofia del Diritto, IV Serie, LXXV, aprile-giugno. 1998.

STOKKE, Hugo. Modernization without westernization? Asian values and human rights discourse in east and west. En: BRUUN, Ole; JACOBSEN, Michael. Human rights and asian values. Contesting national identities and cultural representations in Asia. Richmond: Curzon, Nordic Institute of Asian Studies, 2000. 